\title{
Small stress protein Hsp27 accumulation during dopamine- mediated differentiation of rat olfactory neurons counteracts apoptosis
}

Patrick Mehlen $^{\star, 1}$, Valérie Coronas ${ }^{2}$, Vesna Ljubic-Thibal ${ }^{3}$, Cécile Ducasse $^{3}$, Laure Granger ${ }^{1}$, Francois Jourdan ${ }^{2}$ and André-Patrick Arrigo ${ }^{3}$

1 Apoptosis/Differentiation Laboratory, CNRS-UMR-5534, Claude Bernard University, Lyon-I, F-69622 Villeurbanne, France

${ }^{2}$ Neurosciences and Olfaction, Claude Bernard University, Lyon-I, F-69622 Villeurbanne, France

${ }^{3}$ Stress Laboratory, CNRS-UMR-5534, Claude Bernard University, Lyon-I, F-69622 Villeurbanne, France

* corresponding author: Patrick Mehlen, Apoptosis/Differentiation, CNRS UMR 5534, Université Claude Bernard, LYON I, 43 bd du 11 Novembre. 69622 Villeurbanne

Received 23.4.98; revised 12.10.98; accepted 25.11.98

Edited by D.Green

\begin{abstract}
The small stress protein Hsp27 is expressed during mammalian neural development. We have analyzed the role of this protein in immortalized rat olfactory neuroblasts. In the presence of dopamine a fraction of these cells differentiate into neurons while the remaining cells undergo apoptosis. We report here that the dopamine induced differentiation and apoptosis are associated with a transient and specific accumulation of Hsp27. Moreover, transfection experiments have shown that Hsp27 overexpression drastically decreases the fraction of cells undergoing apoptosis. In contrast, reduction of the endogenous level of Hsp27 led to abortion of differentiation and, therefore, drastically increased the number of apoptotic cells. Furthermore, in the normal cell population we show that Hsp27 accumulation takes place only in differentiating cells that were not undergoing apoptosis. We therefore conclude that Hsp27 may represent a key protein that controls the decision of olfactory precursor cells to undergo either differentiation or cell death.
\end{abstract}

Keywords: apoptosis; differentiation; dopamine; Hsp27; olfactory neurons; stress protein

Abbreviations: sHsp, small heat shock protein; DA, dopamine

\section{Introduction}

Small stress proteins (sHsp) belong to the family of heat shock (or stress) proteins. ${ }^{1}$ Between species, sHsp show greater variation than other stress proteins (i.e. Hsp70), in sequence, in molecular mass and in number. ${ }^{2}$ For example, four sHsp exist in Drosophila and mammals (Hsp27, $\alpha \mathrm{B}$-crystallin, Hsp20 and $\mathrm{HspB} 2)^{2-4}$ while plants contain more than 20 different sHsp. ${ }^{5} \mathrm{sHsp}$ are oligomeric proteins which share homology to the major eye lens proteins, $\alpha \mathrm{A}$ - and $\alpha \mathrm{B}$-crystallin. ${ }^{6}$ Mammalian Hsp27 and $\alpha \mathrm{B}$-crystallin are phosphoproteins ${ }^{2}$ whose expression confers cellular thermotolerance, ${ }^{7,8}$ resistance to cytotoxic drugs ${ }^{9-12}$ and protection against oxidative stress- and TNF $\alpha$-induced cytotoxicity. ${ }^{9,13-17}$ Recently, we and others have reported that $\mathrm{sHsp}$ are also negative regulators of apoptosis. ${ }^{18-20}$ For example, constitutive expression of mammalian Hsp27 can interfere with the death mediated by numerous apoptotic stimuli, such as Fas/APO-1 activation, staurosporine and etoposide. Moreover, we have recently observed that the in vitro anti-apoptotic effect of Hsp27 leads in vivo to an increased tumorigenesis of rat colon cancer cells. $^{21}$

The molecular basis of the sHsp protective function is still unknown but could be related to the in vitro ATPindependent chaperone activity associated with these proteins that prevents the heat-induced aggregation of substrate proteins. ${ }^{22,23}$ In heat-treated cells, large oligomers of sHsp are thought to serve as reservoirs of non native protein intermediates maintained in a folding competent state s4,25 $^{24}$ hence preventing further aggregation of non-native proteins and therefore enhancing their refolding by ATP-dependent chaperones (i.e. Hsp70 and co-chaperones). We have recently proposed that the large oligomers of mammalian Hsp27 represent the active form of this protein during early differentiation ${ }^{26,27}$ or in response to oxidative stress. ${ }^{18,28} \mathrm{~A}$ specific protective activity against the stress-induced disruption of the actin microfilament network was also proposed, ${ }^{17,29}$ which probably results from the in vitro actin capping-decapping activity associated with Hsp27 small oligomers. ${ }^{30}$ Finally, we have suggested that $\mathrm{sHsp}$ also have the ability to modulate reactive oxygen species and glutathione levels, a phenomenon leading to the inhibition of cell death. ${ }^{16}$

sHsp share the intriguing property of tissue specific expression during development (reviewed $\mathrm{in}^{2,31}$ ), particularly during maturation of the nervous system (reviewed $\mathrm{in}^{32}$ ). This phenomenon has been extensively studied in Drosophila where three out of the four sHsp display a pattern of developmental expression in gonads, imaginal discs and the nervous system. ${ }^{33-35}$ In mammals, while Hsp27 (denoted Hsp25 in mouse) expression is restricted to specific motoneurons and primary sensory neurons of adult rat brain, ${ }^{36}$ a massive expression of this protein is detected, through days 13 to 20 of mouse development, in neurons of the spinal cord and Purkinje cells ${ }^{37}$ or at the area of neural tube closure. ${ }^{38}$ The role of $\mathrm{sHsp}$ expression during nervous system development is unknown but could be related to a specific role during cell differentiation. Indeed, in vitro $\mathrm{sHsp}$ share the property of transient 
expression during cellular differentiation of all cell types so far tested. ${ }^{2}$ In mouse embryonic stem cells, inhibition of this expression leads to abortion of differentiation and massive commitment to apoptosis. ${ }^{27}$

The role of Hsp27 during neural differentiation was studied in immortalized rat olfactory neuronal progenitor 13.S.1.24 cells. In the presence of dopamine, a fraction of these cells undergo neuronal differentiation while the remaining population die by apoptosis. ${ }^{39}$ We show here that dopamine provokes a transient and specific accumulation of Hsp27. Modulation of Hsp27 level led to the conclusion that this protein is a key element which controls the balance between differentiation and cell death Furthermore, we present evidence which suggest that differentiating neural cells escape from apoptosis by transiently accumulating high levels of Hsp27.

\section{Results}

We reported recently that specific subpopulations within cultured 13.S.1.24 cells were committed to either death or neuronal differentiation when exposed to DA or DA agonists. $^{39}$ Several DA concentrations $(20-80 \mu \mathrm{M})$ have been assessed and have been shown to lead to either more differentiation (low DA concentration) or to more cell death (high DA concentration). For these experimental conditions, we have determined the level of $\mathrm{Hsp} 27$ by immunoblot analysis. Figure 1 shows the kinetic analysis of the level of Hsp27 in 13.S.1.24 cells treated with the two extreme DA concentrations, 20 (A) or 80 (B) $\mu$ M DA. A low level of Hsp27 (see also Figure $2 A$ where ten times more total protein has been loaded) is expressed in untreated neuronal progenitors while a high level of this protein can be detected after DA treatments. This accumulation is transient and peaks $12-$ $24 \mathrm{~h}$ after DA treatment. A similar effect was observed with intermediate doses of DA such as 40 and $60 \mu \mathrm{M}$ (not shown). A control experiment was performed by analyzing the level of the main stress protein, Hsc70/Hsp70. An immunoblot analysis using an antiserum raised against Hsc and Hsp70 has shown that the highest DA treatment $(80 \mu \mathrm{M})$ leads to a slight decrease of $\mathrm{Hsc70}$ while $\mathrm{Hsp} 70$ remains non detectable (Figure 1C). A densitometric analysis of $\mathrm{Hsp} 27 / \mathrm{Hsc70}$ behavior in response to DA is presented in Figure 1D. Hence, DA treatment does not induce a stress response (i.e. monitoring by $\mathrm{Hsp} 70$ accumulation) but leads to a drastic and specific accumulation of Hsp27 in 13.S.1.24 cells.

We next investigated whether Hsp27 accumulation in response to DA was related to the process of differentiation. 13.LA.tet2 cells, derived from 13.S.1.24 cells by stable integration of tTA transactivator gene, were transiently transfected with either a control vector (cont.) or vectors containing human Hsp27 coding sequence placed in normal (hsp27+) or reverse orientation (hsp27-) under the control of tTA dependent promoter (see Materials and Methods). Transfection efficiency was more than 50\% (not shown). Immunoblot analysis of the sHsp cellular contain was performed $24 \mathrm{~h}$ after transfection (Figure 2A). The accumulation of $\mathrm{Hsp} 27$ represented about $220 \%$ of that of the endogenous protein. The reverse phenomenon was observed when the anti-sense vector was used. In this case, the level of endogenous Hsp27 was decreased by about $70 \%$ (Figure $2 \mathrm{~A}$ ).

The transiently transfected cells described above were treated with $40 \mu \mathrm{M}$ DA and expression of the olfactory marker protein (OMP), a specific marker for differentiated olfactory neurons, was determined. An intermediate dose of DA $(40 \mu \mathrm{M})$ was chosen since this concentration allows a relatively equal amount of cell death and differentiation (Figures $2 \mathrm{~B}$ and $3 \mathrm{~B}$ ). Figure $2 \mathrm{~B}$ describes a quantitative
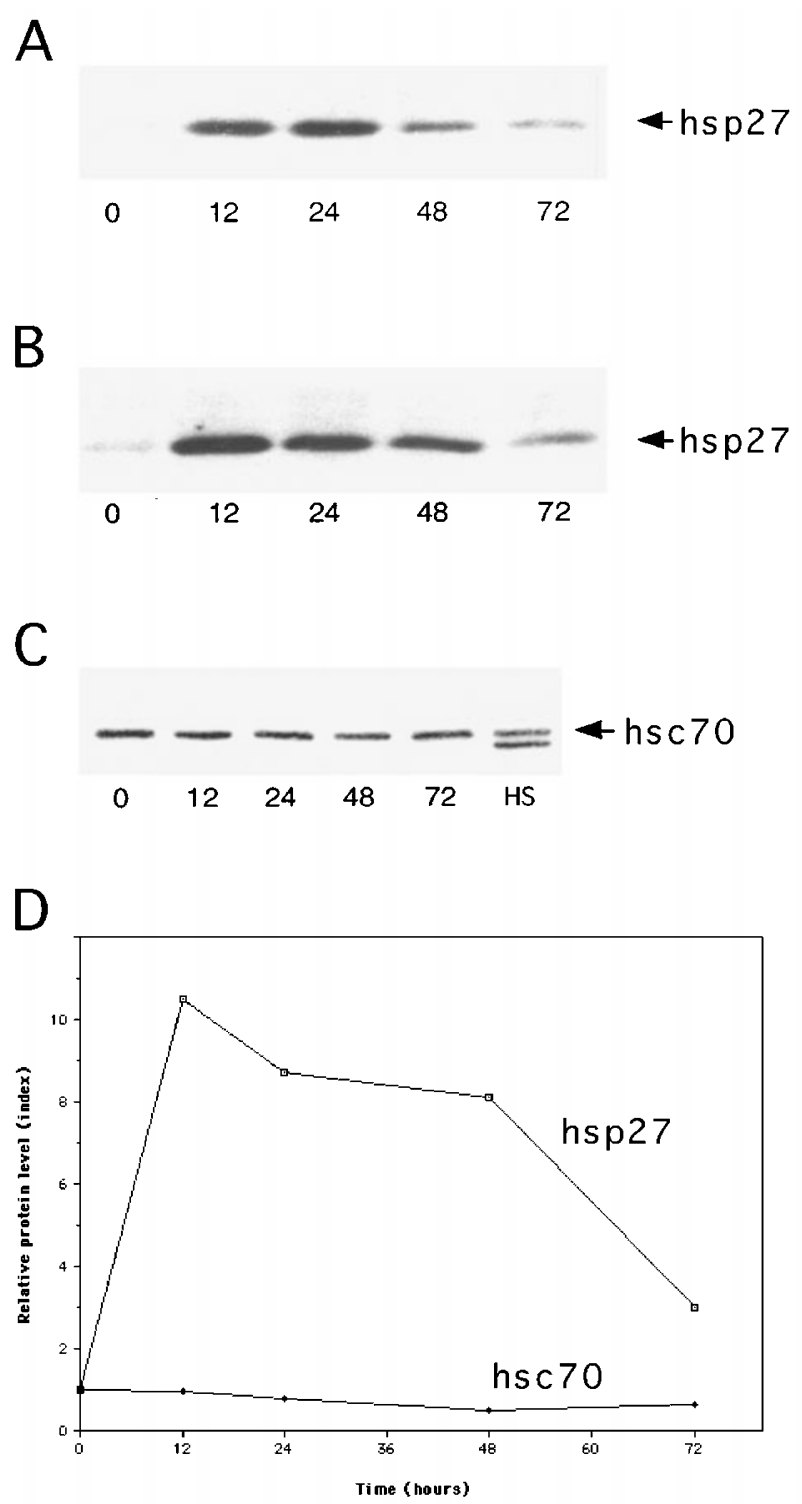

Figure 1 Dopamine induces a specific and transient Hsp27 accumulation in 13.S.1.24 cells. 13.S.1.24 cells were either kept untreated (0) or treated for the time indicated with $20 \mu \mathrm{M}(\mathbf{A})$ or $80 \mu \mathrm{M}(\mathbf{B}$ and $\mathbf{C})$ DA in the presence of $100 \mu \mathrm{M}$ ascorbic acid. Immunoblot analysis of $10 \mu \mathrm{g}$ of total protein was then performed as described in Materials and Methods using antibodies raised against either Hsp27 (A and B) or Hsc/Hsp70 (C). In C, a heat shock of 30 min at $43^{\circ} \mathrm{C}$ followed by $20 \mathrm{~h}$ of recovery has been performed (HS). The detection was performed using ECL chemiluminescence system. (D) Densitometric analysis of $\mathbf{B}$ and $\mathbf{C}$. Note the strong but transient accumulation of $\mathrm{Hsp} 2712 \mathrm{~h}$ after dopamine treatment 


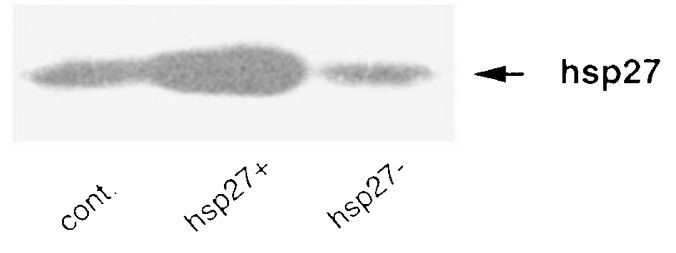

B
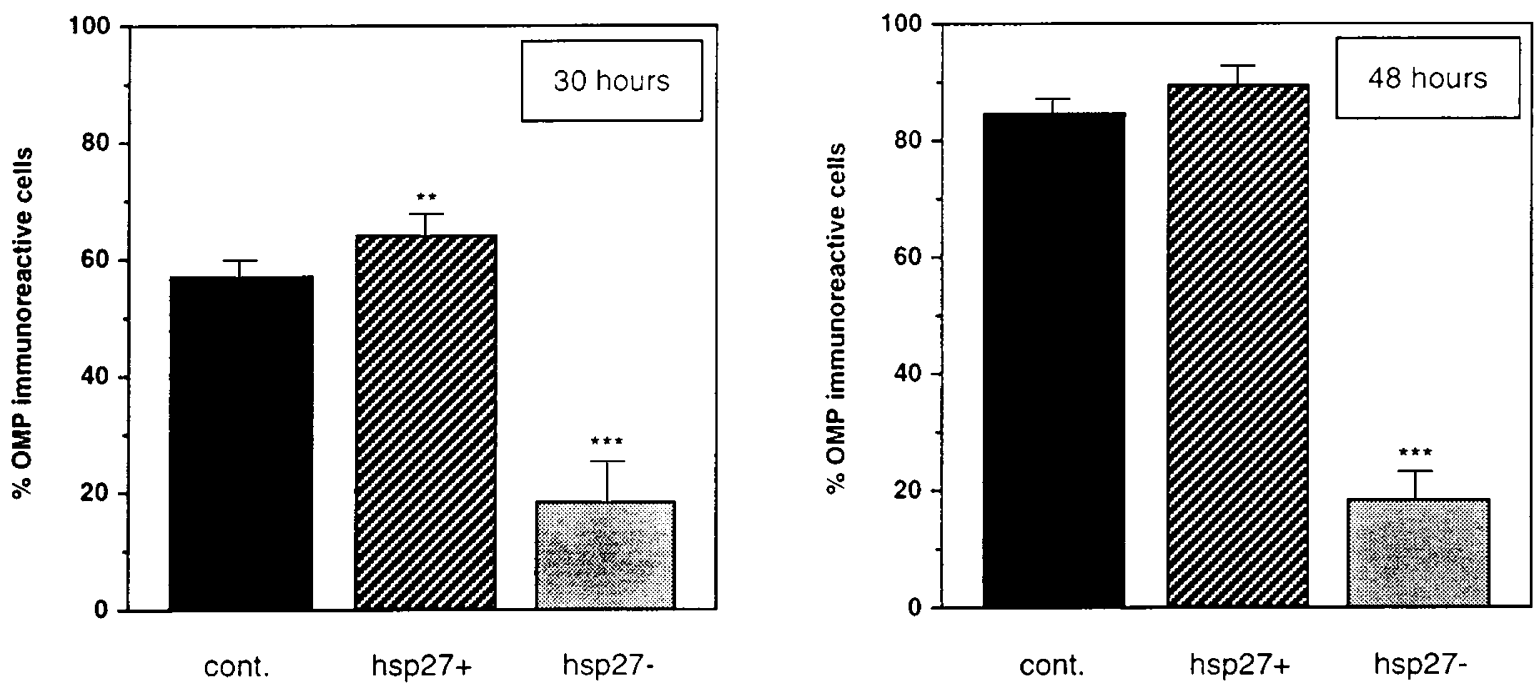

C
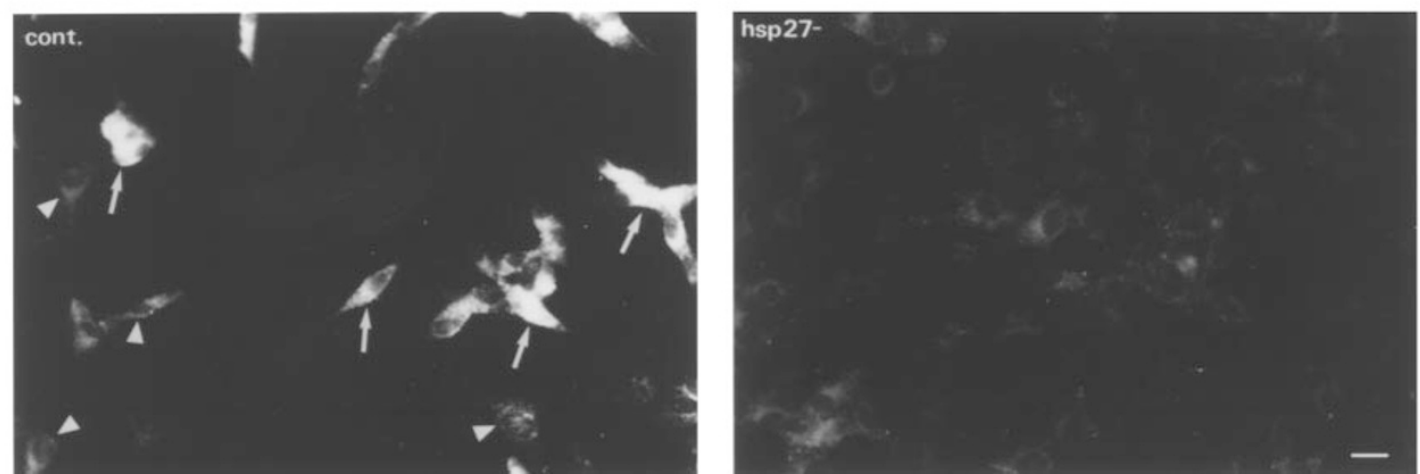

Figure 2 Change in Hsp27 level drastically modulates DA-mediated differentiation of olfactory neuroblasts. 13.LA.tet2 cells were transfected with control pUH103 (cont.), Hsp27 sense pUH10-3Hhsp27 (hsp27+) or anti-sense pUH10-3Hanthsp27 (hsp27-) vectors. Twenty-four hours after transfection, cells were either immediately harvested and loaded (100 $\mu \mathrm{g}$ of total protein) on a gel for subsequent Hsp27 immunoblot (A) or treated with $40 \mu \mathrm{M}$ DA in the presence of ascorbic acid for 30 or $48 \mathrm{~h}$ (B and $\mathbf{C}$ ) before being fixed and prepared for immunofluorescence analysis performed with OMP antiserum (see Materials and Methods). (A) Immunoblot analysis of Hsp27 cellular content. The increased signal in hsp27+ cells reflects the accumulation of human Hsp27. The decreased level in hsp27cells is due to the lack of production of endogenous Hsp27. (B) Differentiation of olfactory progenitors was monitored as the percentage of OMP immunoreactive cells calculated by dividing the number of OMP positive cells by the total number of cells. This experiment is one of three distinct experiments leading to similar results. An average number of 975 cells was counted in 20 fields. Significantly different from control: ${ }^{* * *} P<0.001,{ }^{* *} P<0.01$ (non linear binomial test). (C) Immunofluorescence detection of OMP in 13.LA.tet2 cells submitted for $30 \mathrm{~h}$ to $40 \mu \mathrm{M}$ of DA. (cont.) 13.LA.tet2 cells transfected with control vector: note that numerous cells display a strong cytoplasmic immunoreactivity (arrows) whereas other cells showed only a faint granular autofluorescence (arrowheads). Both types of cells are either scattered in the plate or gather into small clusters. (hsp27-) 13.LA.tet2 cells transfected with Hsp27 anti-sense vector: note that most cells display the faint granular autofluorescence typical of non-immunoreactive cells. Scale bar: $20 \mu \mathrm{m}$ 
analysis of the number of transfected 13.LA.tet2 cells expressing OMP in response to DA. After $30 \mathrm{~h}$ of treatment, a slight but significant increase in the number of OMP positive cells was detected in the human Hsp27 expressing (hsp27+) cellular population (control: $56 \% \pm 2.6$, hsp27+: $64.8 \pm 3.52$ ). After $48 \mathrm{~h}$ of DA treatment, this slight increase in Hsp27 overexpressing cells is no longer significant, hence suggesting that expression of human Hsp27 only slightly and transiently increased the rate of OMP immunoreactivity. However, after 30 or $48 \mathrm{~h}$ of DA treatment, only a small number of OMP positive cells was observed among cells underexpressing Hsp27 (hsp27-) compared to the control population (30 h: $18.6 \% \pm 6.44$ versus $56 \% \pm 2.6$ ) (Figure $2 \mathrm{~B}$ and $\mathrm{C}$ ). Morphological analysis based on the bipolar appearance of differentiated cells led to the similar conclusion (Figure 2C and not shown) that underexpression of the endogenous Hsp27 drastically reduced the frequency of the differentiated phenotype. Hence, the level of Hsp27 probably represents a key element in the differentiation of progenitors into mature neurons.

As DA treatment not only provokes differentiation but also cell death, we have analyzed the effect mediated by different levels of Hsp27 on DA induced cell death. 13.LA.tet2 cells were transfected as described above and cell death was monitored $60 \mathrm{~h}$ after addition of $40 \mu \mathrm{M}$ DA (see Materials and Methods). At this particular time point, the switch between differentiation and death has been achieved. Cell death, which begins to be detectable less than $24 \mathrm{~h}$ after adding DA to cells, ${ }^{39}$ was monitored by flow cytometry analysis of propidium iodine (PI) incorporation (see Materials and Methods). Cells not treated with DA demonstrated a low rate of death (about 7\%) (Figure $3 \mathrm{~A}$ and not shown). In contrast, a $40 \mu \mathrm{M}$ DA treatment induced the death of about $59 \%$ of the control cells (Figure 3B). Overexpression of $\mathrm{Hsp} 27$ led to an important decrease of DA-mediated cell death (30\%), while a massive increase in the percentage of dying cells was observed in cells underexpressing Hsp27 (82\%) (Figure 3C and D). Hence, the level of Hsp27 appears to play a major role in the control of DA-mediated cell death of olfactory progenitor cells.

To more precisely understand the role of Hsp27 in DA treated olfactory progenitor cells, we have compared the level of this protein in differentiating or pre-apoptotic cells. 13.S.1.24 cells were treated for $24 \mathrm{~h}$ with DA, then cell sorting of either living (gate R1) or early apoptotic cell (gate R2) sub-populations was performed as described in Materials and Methods. The Western blot analysis presented in Figure 4 shows that Hsp27, which strongly accumulates $24 \mathrm{~h}$ after DA addition (Figure $1 \mathrm{~A}$ and $\mathrm{B}$ ), is concentrated in differentiating cells and almost absent in cells undergoing apoptosis. Hence, these results strongly suggest that Hsp27 accumulates in differentiating cells to allow their escape from apoptosis.

\section{Discussion}

The present study has led to the determination of a role for Hsp27 during the differentiation of olfactory neuronal progenitors. It is, to our knowledge, the first report describing a sHsp function in a neuronal cell line. We show here that Hsp27 transiently and specifically accumulates in differentiating neuronal progenitors. As already observed in several other differentiating systems, Hsp27 accumulation peaks during early differentiation, and the level of this protein drastically recedes soon after the appearance of differentiation markers. ${ }^{26,27,40-42}$ The results presented here therefore confirm that Hsp27 plays a role during early differentiation and is probably of no more use during late differentiation.

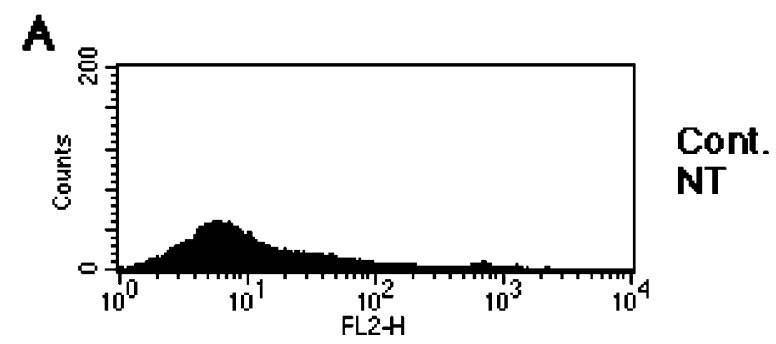

B
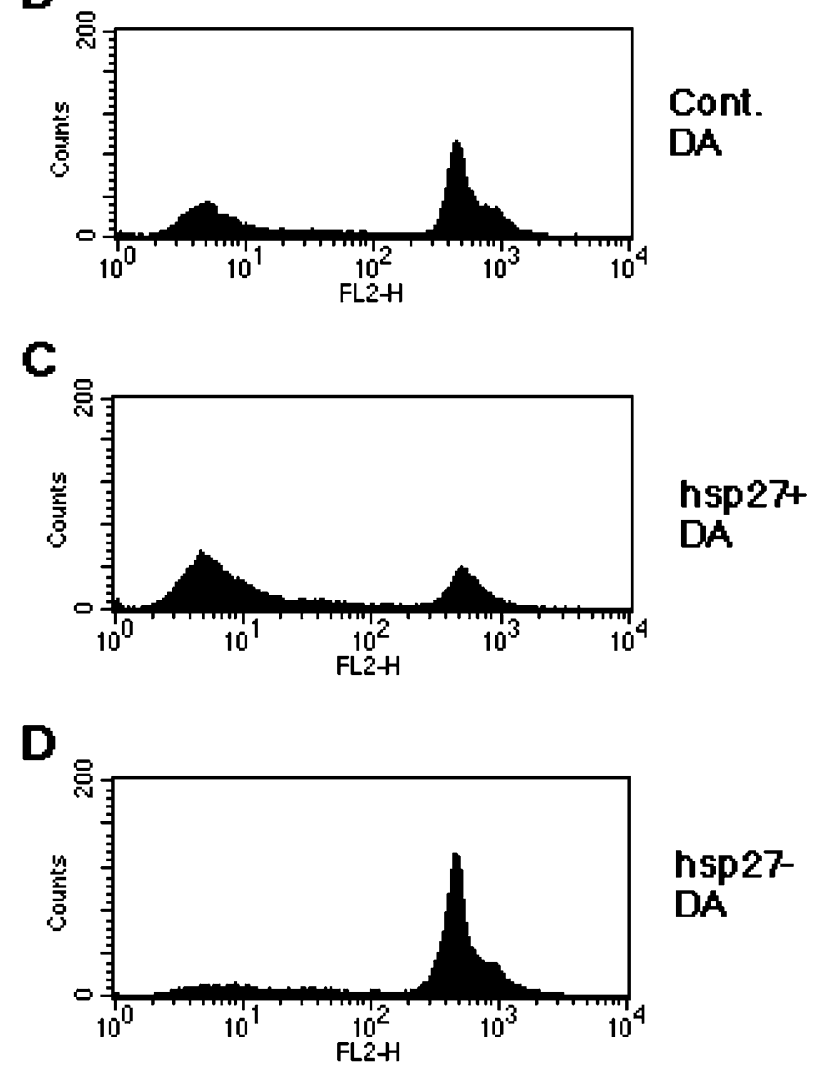

Figure 3 Change in Hsp27 levels modulates dopamine induced cell death. 13.LA.tet2 cells were transfected with control pUH10-3 (cont.) (A and B), Hsp27 expressing pUH10-3Hhsp27 (hsp27+) (C) or Hsp27 anti-sense pUH103 Hanthsp27 (hsp27 -) (D) vectors. Twenty-four hours after transfection, cells were treated (DA) or not (NT) with $40 \mu \mathrm{M}$ dopamine in the presence of ascorbic acid for $48 \mathrm{~h}$. Cell death was monitored by PI incorporation as described in Materials and Methods. Results are presented as histogram plots showing the number of cells (counts) versus PI fluorescence (FL2-H). Note the direct relation between Hsp27 expression and cell survival 


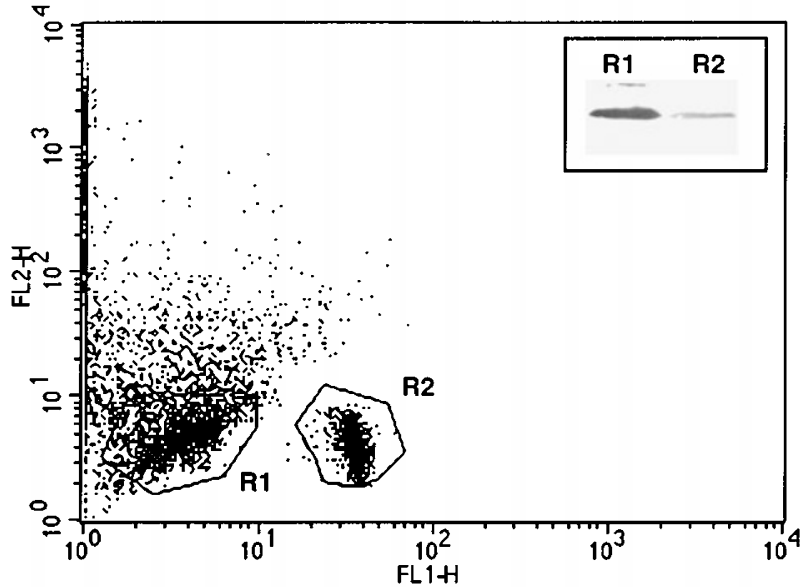

Figure 4 Hsp27 specifically accumulates in cells escaping from apoptosis. 13.S. 1.24 cells were treated for $24 \mathrm{~h}$ with $40 \mu \mathrm{M}$ DA in the presence of ascorbic acid. FACS analysis was performed using PI and annexin V labelling as described in Materials and Methods. Cell sorting was performed on either ' $P I$ and annexin V negative cells' (alive cells, gate R1) or 'PI negative and annexin $\checkmark$ positive' (cells undergoing early apoptosis, gate R2) subpopulation. $5.10^{5}$ cells of each sub-population were then loaded on a $15 \%$ acrylamide gel and Hsp27 level was determined by immunoblot analysis using ECL+ chemiluminescence system. Note that Hsp27 is present in live cells and almost absent in cells undergoing apoptosis

Remarkably this in vitro system allows the analysis of both differentiation and apoptosis, since large subpopulations of cells were committed to either death or to neuronal differentiation. We show here that variations in Hsp27 levels lead to a modulation of both differentiation and apoptosis processes. While high levels of Hsp27 provoke a slight increase in the rate of differentiation and an important decrease in cell death, the underexpression of endogenous Hsp27 is associated with a complete failure of differentiation and a massive commitment to cell death. These results confirm our previous observation that Hsp27 underexpression aborts the differentiation of totipotent murine embryonic stem cells ${ }^{27}$ and that sHsp can interfere with Fas/ APO-1, staurosporine and etoposide induced apoptosis. ${ }^{18,19}$

The fact that Hsp27 overexpression only slightly and transiently modulates the differentiation efficiency but strongly blocks the process of neural cell death suggests that Hsp27 does not really act as a mediator of differentiation but rather as an inhibitor of cell death. Besides, our finding that Hsp27 accumulates only in cells that have escaped from apoptosis leads to the same conclusion and strongly suggests that Hsp27 is a key element in the control of cell death during neuronal differentiation. Interestingly, Hsp27 definitely differs from the other anti-apoptotic proteins by the fact that it naturally accumulates during differentiation and specifies, in the same population, differentiating cells from cells which will undergo apoptosis. How and why, in the same population submitted to DA, some neural progenitors accumulate Hsp27 and consequently undergo differentiation and others do not accumulate this protein and die remains to be shown. A preliminary study has suggested that the switch allowing either accumulation of Hsp27 or cell death is downstream of the DA D2 receptor since CAMP, its second messenger, allows a similar accumulation of Hsp27 (Ducasse and Arrigo, unpublished observations). Further studies need now to address the signal transduction pathway(s) leading to this differentiation-dependent accumulation of Hsp27.

The molecular mechanism allowing Hsp27 to protect differentiating neural cells from apoptosis is unknown. We have reported previously that Hsp27 protects against Tumor Necrosis Factor induced cell death via the control of reactive oxygen species (ROS). However, the protection observed here is probably related to other mechanisms since the dopamine induced apoptosis in 13.S.1.24 cells occurs even in the presence of anti-oxidant. ${ }^{39}$ However ROS are not the only mediator of cell death related to redox modulation. Indeed, several pieces of evidence have converged toward the importance of glutathione in the control of apoptosis. ${ }^{43}$ In this respect, we have shown that Hsp27 expression in cells, that are normally devoid of this protein, upregulates glutathione levels leading to decreased ROS level and a global pro-reduced state. ${ }^{16}$ Remarkably, during differentiation of embryonic stem cells Hsp27 transient accumulation is accompanied by an increase in glutathione. ${ }^{44}$ On the other hand, several data have strengthened the hypothesis that Hsp27 induced protection against apoptosis can be independent of glutathione (Mehlen and Arrigo, unpublished observations) but rather dependent upon its ability to bind specific proteins such as actin ${ }^{30}$ or proteasome subunit (Boelens, personal communication). Hence, a protein controlling actin polymerization could be of great interest, particularly during differentiation of cells with specific morphology such as neural cells. Likewise, proteasome activity seems to be involved both in neural cell death ${ }^{45}$ and in neural differentiation. ${ }^{46} \mathrm{~A}$ protein controlling proteasome activity could then represent a check point between apoptosis and differentiation. Future studies need to address the molecular function of Hsp27 in this system.

It is now tempting to speculate that this in vitro transient Hsp27 accumulation observed in differentiating olfactory progenitors could then be related to the in vivo cell-specific and developmental stage-specific pattern of sHsp expression in the developing nervous system. ${ }^{34,35}$ Hence, in these neuronal tissues, one in vivo function of Hsp27 could be of selecting differentiating neurons either to die or to carry on their differentiation process. To clarify this point, we are currently investigating the in vivo relationship between Hsp27, apoptosis and differentiation in the rat olfactory system.

\section{Materials and Methods}

\section{Cells and dopamine treatment}

The immortalized neuroblast 13.S.1.24 cells have been described previously. ${ }^{39}$ They were grown in Dulbecco's modified Eagle's medium (DMEM) supplemented with 10\% heat-inactivated fetal calf serum (Gibco, BRL) and $0.3 \mathrm{mg} / \mathrm{ml}$ of gentamycine (Gibco, BRL). For dopamine treatments, cells were plated at a density of 50000 cells/ 
$\mathrm{cm}^{2}$ and fed with DMEM $10 \%$ FCS (day 0) then DMEM $5 \%$ (day 1). On day 2 of culture, $20-80 \mu \mathrm{M}$ of dopamine and $100 \mu \mathrm{M}$ of ascorbic acid were added to the media and cell death or differentiation was monitored $24-48 \mathrm{~h}$ later.

\section{Immunoblotting}

One dimensional immunoblots using antibodies raised against Hsp $27^{47}$ or Hsp70 (StressGen, Tebu, France) were performed as already described. ${ }^{15,47}$ They were revealed with the ECL or ECL+ kit from Amersham Corp. (UK) and autoradiographs were recorded onto X-Omat AR films (Eastman Kodak Co, Rochester). A Bioprofil system (Vilber Lourmat, France) was used for quantification. The analysis was performed within the range of proportionality of the film.

\section{Transfections}

13.LA.tet2 cells were derived from 13.S.1.24 cells by the stable transfection of modified pUHD15-1 plasmid coding for Tetracycline repressor-herpes simplex virus transactivator protein VP16 (TTA). ${ }^{48}$ Briefly, 13.S. 1.24 cells $\left(10^{6}\right)$ were plated in $100 \mathrm{~mm}$ dishes and transfected using lipofectamine procedure according to manufacturer instruction with $2 \mu \mathrm{g}$ of pUHD15-1-puro plasmid and $9 \mu \mathrm{l}$ of lipofectamine. Forty-eight hours after transfection, puromycin was added and clones were isolated about 3 weeks later. Characterization of positive clones was performed as described previously. ${ }^{48}$ 13.LA.tet2 cells have been shown to behave as 13.S.1.24 cells in their ability to differentiate or undergo apoptosis in response to dopamine treatment. To modulate Hsp27 level, 13.LA.tet2 cells, grown in absence of tetracycline, were transiently transfected with control pUH10-3, ${ }^{48}$ pUH10-3Hhsp27, and pUH10-3Hanthsp27 vectors using lipofectamine procedure. ${ }^{16,18}$ pUH10-3Hhsp27 and pUH103 Hanthsp27 plasmids were derived from pUH10-3 plasmid by cloning the $E c o R I-E c o R I$ fragment containing the coding sequence of human $\mathrm{Hsp} 27^{14,27}$ respectively in normal or reverse orientation in EcoRI site of pUH10-3 polylinker. Cells were plated at a density of 50000 cells/ $\mathrm{cm}^{2} 24 \mathrm{~h}$ before transfection and were dopamine treated $24 \mathrm{~h}$ later.

\section{Analysis of dopamine induced apoptosis}

Apoptosis of 13.S.1.24 or 13.LA.tet2 cells was analyzed $24 \mathrm{~h}$ after dopamine treatment using the annexin $\mathrm{V}$ procedure following the manufacturer's instructions (Boehringer Mannheim, France). Briefly, collected cells were washed in $\mathrm{Ca}^{2+}$ containing buffer (10 mM HEPES/ $\mathrm{NaOH}, \mathrm{pH} 7.4 ; 140 \mathrm{mM} \mathrm{NaCl} ; 2.5 \mathrm{mM} \mathrm{CaCl}_{2}$ ) and incubated for $10 \mathrm{~min}$ in the presence of annexin V. Cells were then washed prior to propidium iodine $(\mathrm{PI})$ addition. Flow cytometry analysis was performed with a FACS-Calibur (Becton Dickinson, Le Pont de Claix, France) using $488 \mathrm{~nm}$ excitation. Emission filter was $530 \mathrm{~nm}$ for annexin and $610 \mathrm{~nm}$ for PI.

\section{Analysis of dopamine induced cell death}

Sixty hours after dopamine treatment, cell death (necrosis or late apoptosis) was analyzed in 13.LA.tet2 using PI staining. Briefly, cells were washed in PBS buffer and then incubated with Propidium lodine. As above, flow cytometry analysis was performed with as above using $488 \mathrm{~nm}$ excitation and $610 \mathrm{~nm}$ emission filters.

\section{Dopamine induced differentiation analysis}

Differentiation in 13.S.1.24 or 13.LA.tet2 cells was monitored by immunochemistry using an antibody raised against OMP (Olfactory
Marker Protein) as described previously. ${ }^{39}$ Prior to transfection, cells were plated in $10 \mathrm{~mm}$ wells containing coverslips. After transfection and dopamine treatment, cells were rinsed in PBS and fixed for $30 \mathrm{~min}$ at $4^{\circ} \mathrm{C}$ in Bouin's fixative. Immunocytochemistry was then performed using a goat polyclonal antiserum raised against OMP (1:1000 dilution).

\section{Acknowledgements}

We wish to thank $D$. Bredesen for critical reading of the manuscript, $D$. Guillet for excellent technical assistance, B. Mignotte for the gift of the tetracycline system. This work was supported by the following grants: ACC-SV9504063 from the Ministère de la Recherche et de l'Enseignement Supérieur, the Ligue contre le Cancer, the ARC (9186) and the Région Rhône-Alpes (to A.-P.A.) and Région Rhône-Alpes (to A.-P.A. and F.J.).

\section{References}

1. Morimoto RI, Tissieres A and Georgopoulos $C$ (1990) Stress proteins in biology and medicine, C.S.H.L. Press, (ed) (Cold Spring Harbor)

2. Arrigo A.-P and Landry J (1994) Expression and Function of the Low-molecularweight Heat Shock Proteins. In M. RI, T.A. and G.C, (eds) The Biology of Heat Shock Proteins and Molecular Chaperones, (Cold Spring Harbor, NY: Cold Spring Harbor Laboratory Press), pp. 335-373

3. Inaguma $Y$, Hasegawa K, Kato Kand Nishida $Y$ (1996) cDNA cloning of a 20-kDa protein (p20) highly homologous to small heat shock proteins: Developmental and physiological changes in rat hindlimb muscles. Gene 178: 145-150

4. Iwaki A, Nagano T, Nakagawa M, Iwaki T and Fukumaki Y (1997) Identification and characterization of the gene encoding a new member of the alpha-Crystallin/ Small hsp family, closely linked to the alphaB-crystallin gene in a head-to-head manner [In Process Citation]. Genomics 45: 386-394

5. Waters $E R$, Lee GJ and Vierling $E$ (1996) Evolution, structure and function of the small heat shock proteins in plants. J. Exp. Botany 47: 325-338

6. Ingolia TD and Craig E (1982) Four small Drosphila heat shock proteins are related to each other and to mammalian alpha-crystallin. Proc. Natl. Acad. Sci. USA 79: 2360-2364

7. Aoyama A, Steiger R, Frohli E, Schafer R, von Deimling A, Wiestler $O$ and Klemenz R (1993) Expression of alpha B-crystallin in human brain tumors. Int. J. Cancer 55: 760-764

8. Lavoie JN, Gingras-Breton G, Tanguay RM and Landry J (1993) Induction of chinese hamster HSP27 gene expression in mouse cells confers resistance to heat shock. J. Biol. Chem. 268: 3420-3429

9. Huot J, Roy G, Lambert H, Chretien P and Landry J (1991) Increased survival after treatments with anticancer agents of Chinese hamster cells expressing the human Mr 27,000 heat shock protein. Cancer Res. 51: 5245-5252

10. Oesterreich S, Weng C-N, Qiu M, Hilsenbeck SG, Osborne CK and Fuqua SW (1993) The small heat shock protein hsp27 is correlated with growth and drug resistance in human breast cancer cell lines. Canc. Res. 53: 4443-4448

11. Garrido C, Mehlen P, Fromentin A, Hammann A, Assem M, Arrigo A and Chauffert B (1996) Inconstant association between 27-kDa heat-shock protein (Hsp27) content and doxorubicin resistance in human colon cancer cells. The doxorubicin-protecting effect of Hsp27. Eur. J. Biochem. 237: 653-659

12. Garrido C, Ottavi P, Fromentin A, Hammann A, Arrigo AP, Chauffert B and Mehlen P (1997) HSP27 as a mediator of confluence-dependent resistance to cell death induced by anticancer drugs. Cancer Res. 57: 2661-2667

13. Mehlen P, Briolay J, Smith L, Diaz-Latoud C, Pauli D and Arrigo A-P (1993) Analysis of the resistance to heat and hydrogen peroxide stresses in COS cells transiently expressing wild-type or deletion mutants of the Drosophila $27-\mathrm{kDa}$ heat-shock protein. Eur. J. Biochem. 215: 277-284

14. Mehlen P, Mehlen A, Guillet D, Preville X and Arrigo A-P (1995a) Tumor necrosis factor- $\alpha$ induces changes in the phosphorylation, cellular localization, and oligomerization of human hsp27, a stress protein that confers cellular resistance to this cytokine. J. Cell. Biochem. 58: 248-259 
15. Mehlen P, Preville X, Chareyron P, Briolay J, Klemenz R and Arrigo A-P (1995b) Constitutive expression of human hsp27, Drosophila hsp27, or human alpha Bcrystallin confers resistance to TNF- and oxidative stress-induced cytotoxicity in stably transfected murine L929 fibroblasts. J. Immunol. 154: 363-374

16. Mehlen P, Preville X, Kretz-Remy $C$ and Arrigo A-P (1996a) Human hsp27, Drosophila hsp27 and humann $\alpha \mathrm{B}$-crystallin expression-mediated increase in glutathione is essential for the protective activity of these protein against TNF $\alpha$ induced cell death. EMBO J. 15: 2695-2706

17. HuotJ, Houle F, Spitz DR and Landry J(1996) HSP27 phosphorylation-mediated resistance against actin fragmentation and cell death induced by oxidative stress. Cancer Res. 56: 273-279

18. Mehlen $P$, Schulze-Osthoff $K$ and Arrigo A-P (1996b) Small stress proteins as novel regulators of apoptosis-Heat shock protein 27 blocks Fas/APO-1- and staurosporine-induced cell death. J. Biol. Chem. 271: 16510-16514

19. Samali A and Cotter TG (1996) Heat shock proteins increase resistance to apoptosis. Exp. Cell Res. 223: 163-170

20. Arrigo A-P (1998) Small stress proteins: chaperones that act as regulators of intracellular redox and programmed cell death. Biol. Chem. Hoppe Seyler 379: 19-26.

21. Garrido C, Fromentin A, Bonnote B, Favre N, Moute M, Arrigo A-P, Chauffert B, Solary E and Mehlen P. (1999). Hsp27 inhibits apoptosis in vivo and increases tumorigenicity of rat colon cancer cells. Cancer Res. In press.

22. Horwitz J, Huang Q-L and Ding L-L (1992) Alpha-crystallin can function as a molecular chaperone. Proc. Natl. Acad. Sci. USA 89: 10449-10453

23. Jakob U, Gaestel M, Engels K and Buchner J (1993) Small heat shock proteins are molecular chaperones. J. Biol. Chem. 268: 1517-1520

24. Ehrnsperger M, Graber S, Gaestel Mand Buchner J (1997) Binding of non-native protein to $\mathrm{Hsp} 25$ during heat shock creates a reservoir of folding intermediates for reactivation. EMBO J. 16: $221-229$

25. Lee GJ, Roseman AM, Saibil HR and Verling E (1997) A small heat shock protein stably binds heat-denatured model substrates and can maintain a substrate in a folding competent state. EMBO J. 16: 659-671

26. Chaufour S, Mehlen P and Arrigo AP (1996) Transient accumulation, phosphorylation and changes in the oligomerization of $\mathrm{Hsp} 27$ during retinoic acid-induced differentiation of HL-60 cells: Possible role in the control of cellular growth and differentiation. Cell Stress Chaperones 1: 225-235

27. Mehlen P, Mehlen A, Godet J and Arrigo A-P (1997a) hsp27 as a Switch between Differentiation and Apoptosis in Murine Embryonic Stem Cells. J. Biol. Chem. 272: $31657-31665$

28. Preville X, Schultz H, Knauf U, Gaestel M and Arrigo A-P (1998) Analysis of the role of Hsp25 phosphorylation reveals the importance of the oligomerization state of this small heat shock protein in its protective function against TNF $\alpha$ - and hydrogen peroxide-induced cell death. J. Cellular Biochem. 69: 436-452

29. Lavoie JN, Hickey E, Weber LA and Landry J (1993) Modulation of actin microfilament dynamics and fluid phase pinocytosis by phosphorylation of Heat Shock Protein 27. J. Biol. Chem. 268: 24210-24214

30. Benndorf R, Hayess K, Ryazantsev S, Wieske M, Behlke J and Lutsch G (1994) Phosphorylation and supramolecular organization of murine small heat shock protein HSP25 abolish its actin polymerization-inhibiting activity. J. Biol. Chem. 269: $20780-20784$

31. Arrigo A-P (1995) Expression of stress genes during development. Neuropathol. Appl. Neurobiol. 21: 488-491

32. Arrige A-P and Mehlen P (1993) Expression, cellular location of low molecular weight heat shock proteins (hsp20s) during development of the nervous system. In: Heat shock or stress proteins and the Nervous System. R.J. Mayer and I.R. Brown Eds. Neurosciences. Perpectives Series Academic Press. pp: 145-167
33. Haass C, Klein U and Kloetzel PM (1990) Developmental expression of Drosophila melanogaster small heat-shock proteins. J. Cell. Sci. 96: 413-418

34. Pauli D, Tonka C-H, Tissieres A and Arrigo A-P (1990) Tissue-specific expression of the heat shock protein HSP 27 during Drosophila melanogaster development. J. Cell. Biol. 111: 817-828

35. Marin R, Valet J and Tanguay R (1993) hsp23 and hsp26 exhibit distinct spatial and temporal patterns of constitutive expression in Drosophila adults. Dev. Genet. 14: 69-77

36. Plumier JC, Hopkins DA, Robertson HA and Currie RW (1997) Constitutive expression of the 27-kDa heat shock protein (Hsp27) in sensory and motor neurons of the rat nervous system. J. Comp. Neurol 384: 409-428

37. Gernold M, Knauf U, Gaestel M, Stahl J and Kloetzel P-M (1993) Development and tissue-specific distribution of mouse small heat shock protein hsp 25. Dev. Genetics. 14: 103-111

38. Walsh D, LiK, Crowther C, Marsh D and Edwards M (1991) Thermotolerance and heat shock response during early development of the mammalian embryo. In Hightower L and Nover L (eds). Heat Shock and Development. Berlin: SpringerVerlag: $58-70$

39. Coronas V, Feron F, Hen R, Sicard G, Jourdan F and Moyse E (1997) In vitro induction of apoptosis or differentiation by dopamine in an immortalized olfactory neuronal cell line. J. Neurochem. 69: 1870-1881

40. Spector NL, Samson W, Ryan C, Gribben J, Urba W, Welch WJ and Nadler LM (1992) Growth arrest of human B lymphocytes is accompanied by induction of the low molecular weight mammalian heat shock protein. J. Immunol. 148: 1668 1673

41. Spector NL, Ryan C, Samson W, Levine H, Nadler LM and Arrigo A-P (1993) Heat shock protein is a unique marker of growth arrest during macrophage differentiation of HL-60 cells. J. Cell. Physiol. 156: 619-625

42. Spector NL, Mehlen P, Ryan C, Hardy L, Samson W, Levine H, Nadler LM, Fabre $\mathrm{N}$ and Arrigo A-P (1994) Regulation of the $28 \mathrm{kDa}$ heat shock protein by retinoic acid during differentiation of human leukemic HL-60 cells. FEBS Lett. 337: 184 188

43. Van den Dobbelsteen DJ, Nobel CSI, Schlegel J, Cotgreave IA, Orrenius S and Slater AFG (1996) Rapid and specific efflux of reduced glutathione during apoptosis induced by anti-Fas/APO-1 antibody. J. Biol. Chem. 271: 1542015427

44. Mehlen P, Weber L, Hickey E and Arrigo A-P (1997b) Large unphosphorylated aggregates as the active form of hsp27 which controls intracellular reactive oxygen species and glutathione levels and generates a protection against TNF $\alpha$ in NIH-3T3-ras cells. Biochem. Biophys. Res. 241: 187-192

45. Sadoul R, Fernandez PA, Quiquerez AL, Martinou I, Maki M, Schroter M, Becherer JD, Irmler M, Tschopp J and Martinou JC (1996) Involvement of the proteasome in the programmed cell death of NGF-deprived sympathetic neurons. EMBO J. 15: 3845-3852

46. Li S, Li Y, Carthew RW and Lai ZC (1997) Photoreceptor cell differentiation requires regulated proteolysis of the transcriptional repressor Tramtrack. Cell 90: $469-478$

47. Arrigo A-P and Welch $W$ (1987) Characterization and purification of the small 28,000-dalton mammalian heat shock protein. J. Biol. Chem. 262: 15359-15369

48. Guenal I, Sidoti-de Fraisse C, Gaumer S and Mignotte B (1997) Bcl-2 and Hsp27 act at different levels to suppress programmed cell death. Oncogene 15: 347 360 